\title{
Clinicopathological Features of Craniopharyngioma: A 15-Year Study From a Tertiary Care Center in Pakistan
}

\author{
Saroona Haroon ${ }^{1,2,3}$, Anoshia Afzal ${ }^{4}$, Shamail Zia ${ }^{5}$, Syed J. Ali ${ }^{6}$, Fazail Zia ${ }^{7}$, Farozaan Shamail ${ }^{5}$, \\ Muhammad $\operatorname{Irfan}^{8}$, Atif A. Hashmi ${ }^{9}$ \\ 1. Pathology, King's Mill Hospital - Sherwood Forest Hospitals, NHS Foundation Trust, Ashfield, GBR 2. Pathology, \\ Prince Faisal Oncology Centre, King Fahad Specialist Hospital, Buraidah, SAU 3. Pathology, Aga Khan University, \\ Karachi, PAK 4. Pathology, University of Oklahoma Health Sciences Center, Oklahoma City, USA 5. Pathology, Ziauddin \\ University, Karachi, PAK 6. Pathology, Dow University of Health Sciences, Karachi, PAK 7. Pathology, Jinnah Sindh \\ Medical University, Karachi, PAK 8. Statistics, Liaquat National Hospital and Medical College, Karachi, PAK 9. \\ Pathology, Liaquat National Hospital and Medical College, Karachi, PAK
}

Corresponding author: Atif A. Hashmi, atifhashmi345@gmail.com

\section{Abstract}

\section{Introduction}

Craniopharyngiomas (CPs) are benign neoplasms and most common suprasellar tumors. They are more frequent in children, contributing to a significant number of intracranial tumors in the pediatric population and are thought to be arising either from the epithelial remnant cells of the craniopharyngeal duct or from the adenohypophysis epithelium. Two subtypes of CPs exist, namely, adamantinomatous craniopharyngioma (ACP) and papillary craniopharyngioma (PCP). ACP is more common in children with a relatively aggressive clinical course and more frequent relapses than PCP. The study objective was to evaluate the clinicopathological features of CP in our population.

\section{Methods}

We conducted a retrospective observational study in the Department of Histopathology at Aga Khan Hospital, Karachi, Pakistan, over a period of 15 years, from January 2001 to December 2015. All CP cases were included in the study. A total of 207 cases were diagnosed during this period by histopathologists based on histologic features. All slides were retrieved, and diagnosis was confirmed after a reexamination of slides.

\section{Results}

We found that the mean age of diagnosis was $25.59 \pm 14.71$ years, and the median follow-up time was 7 (3-19) years. The number of male patients was 136 (65.7\%) and the number of female patients was 71 (34.3\%). The most common tumor site was suprasellar (71.5\%) followed by the sellar and temporal lobe $(12.1 \%$ and $6.8 \%$, respectively). The most common complaints were headache (21.7\%), followed by loss of vision/decreased vision (16.4\%) and vomiting (5.3\%). The overall survival rate was $95.2 \%$ with a recurrence rate of $5.8 \%$. A significant association of survival was noted with tumor recurrence.

Review began 03/24/2021 Review ended 03/24/2021 Published 03/28/2021

( ) Copyright 2021 Haroon et al. This is an open access article distributed under the terms of the Creative Commons Attribution License CC-BY 4.0., which permits unrestricted use, distribution, and reproduction in any medium, provided the original author and source are credited.

\section{Conclusion}

$\mathrm{CP}$ is a rare brain tumor with good overall survival. We found a low recurrence rate of CP in our study. However, recurrence was found to be the most important factor determining survival in patients with CP.

Categories: Pathology, General Surgery, Neurosurgery

Keywords: craniopharyngioma, papillary craniopharyngioma, adamantinomatous craniopharyngioma

\section{Introduction}

Craniopharyngioma (CP) is a tumor of sellar and suprasellar areas with two histologic subtypes. The adamantinomatous craniopharyngioma (ACP) subtype is usually seen in childhood and is more common, whereas the papillary craniopharyngioma (PCP) subtype is almost exclusive to the adult population [1]. The two subtypes differ in their clinical behavior and overall features. The papillary type is usually indolent, whereas the adamantinomatous type has a relatively aggressive clinical course [2]. The most reported symptoms are headache, decreased/loss of vision, and neuroendocrine abnormalities (hormonal changes, personality changes, etc.). The incidence from recent studies appears to be high in males compared to females [3]. However, previous studies had shown an equal incidence in males and females. Malignant transformation is infrequent and usually occurs after multiple recurrences of CP [4]. ACP is relatively common and tends to recur more frequently than PCP whereas PCP has a benign clinical course with less frequent relapses. The usual treatment approach for both subtypes is resection followed by radiotherapy. The study objective was to evaluate the clinicopathological features of CP in our population. 


\section{Cureus}

\section{Materials And Methods}

We conducted a retrospective observational study in the Department of Histopathology at Aga Khan Hospital (Karachi, Pakistan) over a period of 15 years, from January 2001 to December 2015. All CP cases were included in the study. A total of 207 cases were diagnosed during this period by histopathologists based on histological features. All slides were retrieved, and diagnosis was confirmed after a reexamination of slides. All specimens were received in the histopathology lab. After gross examination and specimen measurement, the tissues were submitted entirely for histopathological examination. A diagnosis of $\mathrm{CP}$ was rendered based on histopathological findings. PCP was characterized by papillary (with fibro-vascular cores) and cauliflower-like morphology, composed of non-keratinizing squamous epithelium. Alternatively, ACP was defined by trabeculae and sheets, with nuclear palisading and stellate reticulum. Nodules of anucleated squames (wet keratin) are characteristic of ACP (Figure 1).
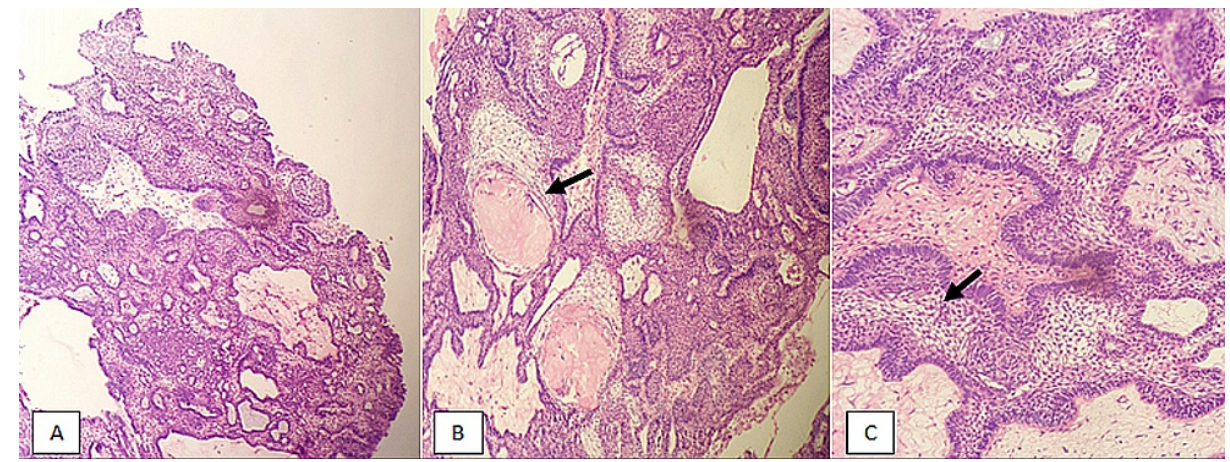

FIGURE 1: Craniopharangioma, adamantinomatous subtype: (A) H\&Estained section at $40 \mathrm{x}$ magnification showing sheets and trabeculae of squamous epithelium; (B) H\&E-stained section at 100x magnification revealing wet keratin (arrow); (C) H\&E-stained section at 400x magnification depicting stellate reticulum (arrow)

H\&E, hematoxylin and eosin

Data analysis was performed using Statistical Package for the Social Sciences, Version 26.0 (IBM Corp, Armonk, USA). Independent t-test and Fisher's exact tests were used to check the association. Survival analysis was done by the Kaplan-Meier method. P-values $<0.05$ were considered as significant.

\section{Results}

We reviewed a total of 207 cases and determined their clinicopathological features. The variables that were studied included age, site, symptoms, gender, tumor subtype, recurrence, and survival. We found that the mean age of diagnosis was $25.59 \pm 14.71$ years, and the median follow-up time was 7 (3-19) years. There were 136 (65.7\%) male patients and 71 (34.3\%) female patients. The most common site was the suprasellar (71.5\%), followed by the sellar and temporal lobe (12.1\% and 6.8\%, respectively). The most common complaints were headache (21.7\%) followed by loss of vision/decreased vision (16.4\%) and vomiting (5.3\%). The overall survival rate was $95.2 \%$ with a recurrence rate of $5.8 \%$ (Table 1 ).

Clinicopathologic characteristics

Age (years), mean $\pm S D$

Follow-up (years), median (range)

Gender

Male, $\mathrm{n}(\%)$

Female, $\mathrm{n}(\%)$

Site

Supraseller, $\mathrm{n}(\%)$

Sellar, $\mathrm{n}(\%)$

Frontal, $\mathrm{n}(\%)$
$136(65.7)$

$71(34.3)$

$148(71.5)$

\section{Values}

$25.59 \pm 14.71$

7 (3-19)

$11(5.3)$ 


\section{Cureus}
Sellar and suprasellar, $\mathrm{n}(\%)$
$9(4.3)$
Temporal, $\mathrm{n}(\%)$
$14(6.8)$
Headache
Yes, n (\%)
$45(21.7)$
No, n (\%)
$162(78.3)$
Vomiting
Yes, n (\%)
$11(5.3)$
No, $n(\%)$
$196(94.7)$
Decreased/loss of vision
Yes, n (\%)
34 (16.4)
No, $n$ (\%)
$173(83.6)$
Fever
Yes, n (\%)
$5(2.4)$
No, n (\%)
202 (97.6)
Generalized weakness
Yes, n (\%)
$5(2.4)$
No, n (\%)
202 (97.6)
Tumor type
Papillary, $n$ (\%)
2 (1)
Adamantinomatous, $\mathrm{n}(\%)$
205 (99)
Recurrence
Yes, $\mathrm{n}(\%)$
$12(5.8)$
No, $n(\%)$
$195(94.2)$
Survival status
Alive, $n(\%)$
197 (95.2)
Expired, $n(\%)$
$10(4.8)$

TABLE 1: Clinicopathological features of the population under study

$\mathrm{SD}$, standard deviation

No significant association of clinicopathological features with recurrence was noted (Table 2).

\begin{tabular}{|c|c|c|c|}
\hline \multirow{3}{*}{ Clinicopathologic characteristics } & \multicolumn{2}{|l|}{ Values } & \multirow{3}{*}{ P-value } \\
\hline & \multicolumn{2}{|l|}{ Recurrence } & \\
\hline & Yes $(n=12)$ & No $(n=195)$ & \\
\hline Age (years) ${ }^{\star}$, mean $\pm S D$ & $28.00 \pm 19.43$ & $25.44 \pm 14.42$ & 0.205 \\
\hline \multicolumn{4}{|l|}{ Gender ${ }^{\star \star}$} \\
\hline Male, $n(\%)$ & $8(66.7)$ & $128(65.6)$ & \multirow{2}{*}{1.000} \\
\hline Female, n (\%) & $4(33.3)$ & $67(34.4)$ & \\
\hline
\end{tabular}




\section{Cureus}

\begin{tabular}{|c|c|c|c|}
\hline \multicolumn{4}{|l|}{ Site $^{\star *}$} \\
\hline Supraseller, n (\%) & $9(75)$ & $139(71.3)$ & \multirow{5}{*}{0.606} \\
\hline Sellar, n (\%) & $1(8.3)$ & $24(12.3)$ & \\
\hline Frontal, n (\%) & $0(0)$ & $11(5.6)$ & \\
\hline Sellar and suprasellar, n (\%) & $0(0)$ & $9(4.6)$ & \\
\hline Temporal, n (\%) & $2(16.7)$ & $12(6.2)$ & \\
\hline \multicolumn{4}{|l|}{ Headache $^{\star *}$} \\
\hline Yes, n (\%) & $3(25)$ & $42(21.5)$ & \multirow{2}{*}{0.726} \\
\hline No, $n(\%)$ & $9(75)$ & $153(78.5)$ & \\
\hline \multicolumn{4}{|l|}{ Vomiting $^{\star \star}$} \\
\hline Yes, n (\%) & $0(0)$ & $11(5.6)$ & \multirow{2}{*}{1.000} \\
\hline No, $n(\%)$ & $12(100)$ & $184(94.4)$ & \\
\hline \multicolumn{4}{|l|}{ Decreased/loss of vision ${ }^{\star \star}$} \\
\hline Yes, n (\%) & $2(16.7)$ & $32(16.4)$ & \multirow{2}{*}{1.000} \\
\hline No, n (\%) & 10 (83.3) & $163(83.6)$ & \\
\hline \multicolumn{4}{|l|}{ Fever ${ }^{\star *}$} \\
\hline Yes, n (\%) & $0(0)$ & $5(2.6)$ & \multirow{2}{*}{1.000} \\
\hline No, n (\%) & $12(100)$ & $190(97.4)$ & \\
\hline \multicolumn{4}{|l|}{ Generalized weakness ${ }^{\star \star}$} \\
\hline Yes, n (\%) & $1(8.3)$ & $4(2.1)$ & \multirow{2}{*}{0.260} \\
\hline No, $n(\%)$ & $11(91.7)$ & $191(97.9)$ & \\
\hline \multicolumn{4}{|l|}{ Tumor type** } \\
\hline Papillary, n (\%) & $0(0)$ & $2(1)$ & \multirow{2}{*}{1.000} \\
\hline Adamantinomatous, n (\%) & $12(100)$ & $193(99)$ & \\
\hline \multicolumn{4}{|l|}{ Survival status ${ }^{\star *}$} \\
\hline Alive, n (\%) & $10(83.3)$ & $187(95.9)$ & \multirow{2}{*}{0.107} \\
\hline Expired, n (\%) & $2(16.7)$ & $8(4.1)$ & \\
\hline
\end{tabular}

\section{TABLE 2: Association of clinicopathologic characteristics of craniopharangioma with tumor}

recurrence

$\mathrm{SD}$, standard deviation

*Independent t-test was applied.

${ }^{* *}$ Fisher's exact test was applied.

Similarly, no significant association of survival status was noted with clinicopathological features (Table 3).

\begin{tabular}{|c|c|c|c|}
\hline \multirow{3}{*}{ Clinicopathologic characteristics } & Values & & \multirow{3}{*}{ P-value } \\
\hline & \multicolumn{2}{|l|}{ Survival status } & \\
\hline & Alive $(n=197)$ & Expired $(n=10)$ & \\
\hline Age $(\text { years })^{*}$, mean $\pm S D$ & $25.79 \pm 14.65$ & $21.60 \pm 16.13$ & 0.380 \\
\hline
\end{tabular}




\section{Cureus}

Gender**

Male, n (\%)

128 (65)

$8(80)$

Female, n (\%)

69 (35)

2 (20)

0.499

Site**

Supraseller, n (\%)

$138(70.1)$

$10(100)$

Sellar, n (\%)

25 (12.7)

0 (0)

Frontal, n (\%)

$11(5.6)$

$0(0)$

0.673

Sellar and suprasellar, n (\%)

9 (4.6)

$0(0)$

Temporal, n (\%)

$14(7.1)$

$0(0)$

Headache**

Yes, n (\%)

43 (21.8)

2 (20)

No, n (\%)

154 (78.2)

$8(80)$

Vomiting**

Yes, n (\%)

10 (5.1)

1 (10)

No, n (\%)

187 (94.9)

$9(90)$

0.428

Decreased/loss of vision ${ }^{\star *}$

Yes, n (\%)

32 (16.2)

2 (20)

No, n (\%)

165 (83.8)

$8(80)$

Fever $^{\star \star}$

Yes, n (\%)

5 (2.5)

$0(0)$

No, n (\%)

192 (97.5)

10 (100)

General weakness**

Yes, n (\%)

5 (2.5)

0 (0)

No, n (\%)

192 (97.5)

10 (100)

1.000

Tumor type $e^{\star *}$

Papillary, n (\%)

2 (1)

$0(0)$

Adamantinomatous, n (\%)

195 (99)

10 (100)

Recurrence $^{\star \star}$

Yes, n (\%)

9 (4.6)

1 (10)

No, n (\%)

188 (95.4)

$9(90)$

TABLE 3: Association of clinicopathologic characteristics of craniopharyngioma with survival status

$\mathrm{SD}$, standard deviation

*Independent t-test was applied.

${ }^{\star \star}$ Fisher's exact test was applied.

Alternatively, significant association of survival was noted with tumor recurrence (Figure 2). 


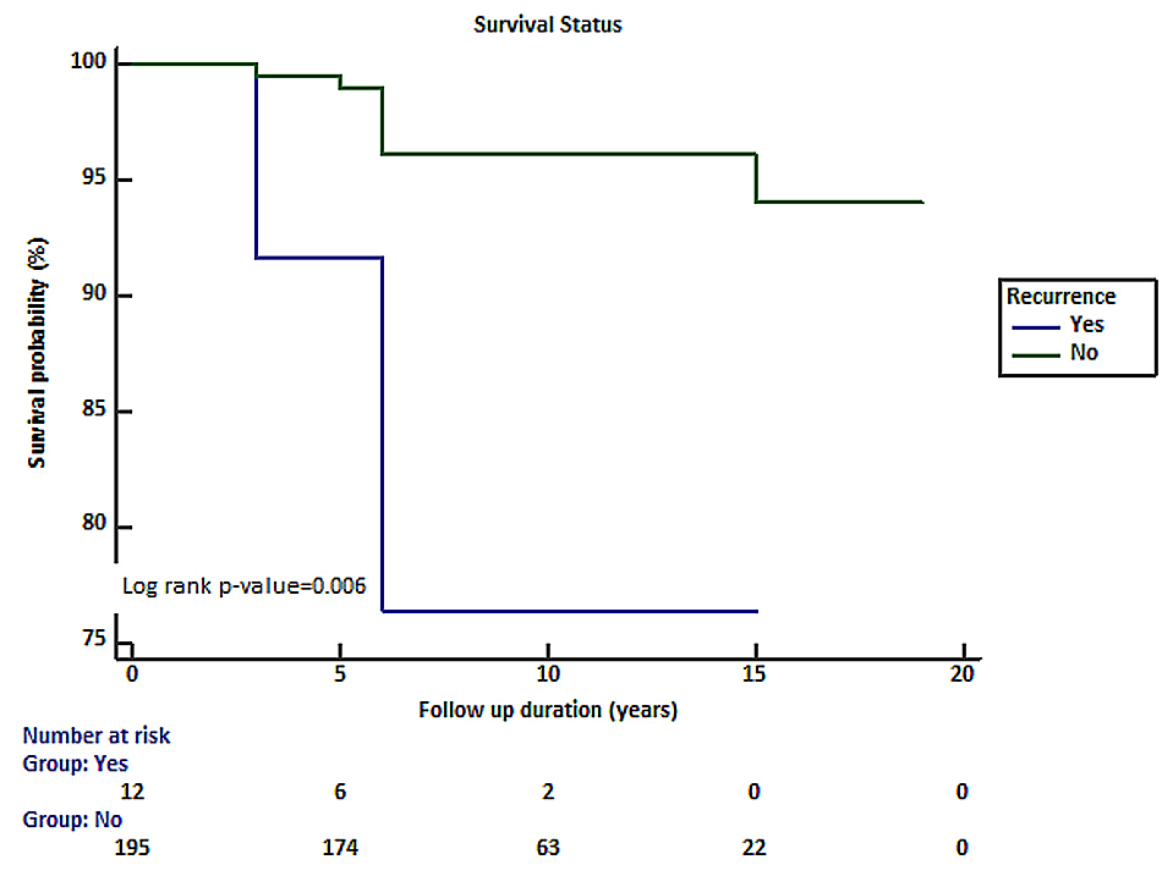

\section{FIGURE 2: Association of recurrence with survival status in patients with craniopharyngioma}

\section{Discussion}

$\mathrm{CP}$ is the most frequent neoplasm of suprasellar and sellar region with ACP being approximately nine times more prevalent than PCP $[1,2]$. Some studies from Pakistan have found the incidence to be greater in the male population [3], but overall CP affects both males and females equally [1-3]. Malignant transformation occurs in CP, especially after multiple recurrences, and some of the reported cases were treated with radiotherapy [4]. Malignant transformation was reported in patients with giant sellar masses and it is recommended to take extra caution if the size of the lesion is large [4].

The size of PCP is usually smaller and the recurrence rate is lower than ACP [5]. Sanford reported the results of a survey and suggested a very good overall outcome in children who were treated with limited surgery and irradiation compared to the attempted total resection [6]. Wara et al. also reported a $77 \% 10$-year diseasefree survival after treatment with radiation and surgery, and advised to follow the patients who underwent total resection without radiation [7].

Schoenfeld et al. also reported better overall outcomes with surgery and radiation compared to gross total resection (GTR) [8]. Other studies also reported that the incidences of endocrinopathies were significantly more with GTR compared with subtotal resection (STR) and radiation [9]. Recent studies have shown that the history of radiation therapy (instead of surgery) is more effective in reducing the resection extent in recurrent cases of craniopharyngioma $[10,11]$.

Based on location and size, differential diagnosis of CP includes pituitary adenoma, epidermoid cyst, and Rathke cleft cyst with squamous metaplasia. Pituitary adenoma is characterized by sheets of monotonous round cells with neuroendocrine appearance. An epidermoid cyst is unilocular lined by keratinizing squamous epithelium. Finally, a Rathke cleft cyst also contains ciliated or mucinous lining that helps in differentiation. In addition, ACPs sometimes show reactive gliosis (piloid gliosis), which sometimes causes confusion and may lead to an erroneous diagnosis of pilocytic astrocytoma. However, the presence of wet keratin and squamous epithelium helps in the correct diagnosis. There is limited role of immunohistochemistry (IHC) in the diagnosis of CP, although ACP is positive with CK7, CK8, CK19 and betacatenin. PCP is positive with BRAF V600E IHC, while ACP is negative. As far as molecular genetics is concerned, ACP is characterized by mutations that activate Wnt pathway gene CTNNB1 encoding $\beta$-catenin in most of the cases, while PCP is characterized by BRAF V600E mutation in more than $90 \%$ of cases $[1,2,6]$.

CPs tend to recur and can cause significant mortality and morbidity due to their critical location and hormonal imbalances, and therefore the recommendation is to prefer STR and radiation therapy over GTR [12].

The limitations of our study included a retrospective study design and limited sample size, especially cases 
of PCP, and therefore, the association of tumor type with recurrence and survival could not be determined. In addition, lack of availability of radiological findings is yet another limitation of the study. Moreover, data regarding GTR versus STR were not available to evaluate the outcome in different treatment groups.

\section{Conclusions}

$\mathrm{CP}$ is a rare suprasellar brain tumor with distinguished histological features. In our study, the ACP subtype of $\mathrm{CP}$ was far more frequent than the PCP subtype. We found an overall low recurrence rate and good survival in patients of CP in our study. We also noted a significant association of disease recurrence of CP with survival in our study. However, more studies are required to have a better idea of clinical course and prognosis of CP in Pakistan, especially the outcome in different treatment groups, for instance, GTR versus STR with radiation.

\section{Additional Information}

\section{Disclosures}

Human subjects: Consent was obtained or waived by all participants in this study. Animal subjects: All authors have confirmed that this study did not involve animal subjects or tissue. Conflicts of interest: In compliance with the ICMJE uniform disclosure form, all authors declare the following: Payment/services info: All authors have declared that no financial support was received from any organization for the submitted work. Financial relationships: All authors have declared that they have no financial relationships at present or within the previous three years with any organizations that might have an interest in the submitted work. Other relationships: All authors have declared that there are no other relationships or activities that could appear to have influenced the submitted work.

\section{References}

1. Larkin SJ, Ansorge O: Pathology and pathogenesis of craniopharyngiomas. Pituitary. 2013, 16:9-17. 10.1007/s11102-012-0418-4

2. Fernandez-Miranda JC, Gardner PA, Snyderman CH, et al.: Craniopharyngioma: a pathologic, clinical, and surgical review. Head Neck. 2012, 34:1036-1044. 10.1002/hed.21771

3. Tariq MU, Din NU, Ahmad Z, Memon W: Papillary craniopharyngioma: a clinicopathologic study of a rare entity from a major tertiary care center in Pakistan. Neurol India. 2017, 65:570-576. 10.4103/neuroindia.NI_552_16

4. Wang F, He Y, Li C, Wang Y, Zhong L: Malignant craniopharyngioma: a report of seven cases and review of the literature. World Neurosurg. 2020, 135:e194-e201. 10.1016/j.wneu.2019.11.111

5. Tavangar SM, Larijani B, Mahta A, Hosseini SM, Mehrazine M, Bandarian F: Craniopharyngioma: a clinicopathological study of 141 cases. Endocr Pathol. 2004, 15:339-434. 10.1385/ep:15:4:339

6. Sanford RA: Craniopharyngioma: results of survey of the American Society of Pediatric Neurosurgery . Pediatr Neurosurg. 1994, 21:39-43. 10.1159/000120860

7. Wara WM, Sneed PK, Larson DA: The role of radiation therapy in the treatment of craniopharyngioma . Pediatr Neurosurg. 1994, 21:98-100. 10.1159/000120869

8. Schoenfeld A, Pekmezci M, Barnes MJ, et al.: The superiority of conservative resection and adjuvant radiation for craniopharyngiomas. J Neurooncol. 2012, 108:133-139. 10.1007/s11060-012-0806-7

9. Sughrue ME, Yang I, Kane AJ, et al.: Endocrinologic, neurologic, and visual morbidity after treatment for craniopharyngioma. J Neurooncol. 2011, 101:463-476. 10.1007/s11060-010-0265-y

10. Dhandapani S, Singh H, Negm HM, et al.: Endonasal endoscopic reoperation for residual or recurrent craniopharyngiomas. J Neurosurg. 2017, 126:418-430. 10.3171/2016.1.JNS152238

11. Younus I, Forbes JA, Ordóñez-Rubiano EG, Avendano-Pradel R, La Corte E, Anand VK, Schwartz TH: Radiation therapy rather than prior surgery reduces extent of resection during endonasal endoscopic reoperation for craniopharyngioma. Acta Neurochir (Wien). 2018, 160:1425-1431. 10.1007/s00701-018$3567-\mathrm{z}$

12. Yang I, Sughrue ME, Rutkowski MJ, et al.: Craniopharyngioma: a comparison of tumor control with various treatment strategies. Neurosurg Focus. 2010, 28:E5. 10.3171/2010.1.FOCUS09307 